\title{
Study on Traditional Techniques in Contemporary Public Sculpture and Its Application in Colleges and Universities
}

\author{
Liu Xiaofei \\ School of Arts, Xi'an University, Xi’an, Shaanxi, China, 710065
}

Keywords: public sculptures; traditional techniques; public art; practical application

\begin{abstract}
Contemporary public sculpture is not only an indispensable part of the urban environment, but also carries the social content and cultural heritage of a city. It shoulders the dual responsibilities of social form and aesthetic consciousness, and becomes a bridge between the public and the city in an open public space. In recent years, along with China's appeal and demand for the return of traditional culture, traditional techniques and ideas of sculpture also show its own importance. However, in an era completely different from the past, contemporary public sculptures should not only have a deep understanding of the application of traditional sculpture techniques, but also draw lessons from them and conform to the needs of the times, so as to realize more possibilities for contemporary public sculptures.
\end{abstract}

\section{Introduction}

As a part of the sculpture art, public sculptures use the expression of space to present an artistic image to the viewer. It usually aims to reflect the social life, the spirit of the times and express the ideas and feelings of the creative subject. At a certain level, public sculpture is a form encompassed by the public art category and both of them have a certain publicity in their creation. This determines that the original intention of creating a public sculpture is not limited to the linguistic language or formal style, but begins with the environmental factors in which it is located, and strives to achieve the integration of the works with urban public space and people. However, public sculpture does not belong to the subordinate form of public art. It has its own independent artistic language and aesthetic value. Public art tells the viewer about the history and culture of a city, and the accumulation of public sculpture works bears the responsibility of promoting the cultural taste of the city. In particular, contemporary public sculptures often quote the elements of traditional sculpture in their works, which reflects the cultural connotations and humanistic spirits of contemporary public art. The development of art always presents its own cycle and regression in the form of reincarnation. After modernism puts the form of art to extremes, art must continue to survive and have to find clues from tradition. Public sculpture, as an art with eternal nature, undoubtedly needs such clues to support its contemporaneity in modeling, volume and material techniques.

\section{The Application of Traditional Sculpture Techniques in Contemporary Public Sculpture}

Like painting, sculpture is also an important part of artistic expression. With the development of science and technology and the impact of modernist art, more and more diverse forms of sculpture reflect the determination of contemporary sculpture against tradition, such as four-dimensional sculpture, five-dimensional sculpture, sound and light sculpture, dynamic sculpture and soft sculpture. However, in the field of contemporary public sculpture, the techniques of traditional sculpture are still used to support its creative process because of the universality and popularity of its audience. From the perspective of creative content, this paper will discuss the references and manifestations of traditional techniques in thematic and signage sculptures, landscape and decorative sculptures, installation and interactive sculptures and stylistic and architectural sculptures. 


\subsection{The application of traditional techniques in thematic and signage sculptures}

The theme of public sculpture is that the work expresses some basic concepts and ideas through the images it creates. This is the core of the content and the source of creation of the public sculpture art. It is the spiritual will and the internal thought that the creator implements in the creative process. Thematicity and signage as an important special certificate of public sculptures have always run through the history of sculpture art. They describe the characteristic language and form of this public sculpture through the reflection of content and form. Due to the special relationship between public sculpture and public space, public sculptures have a public nature at the very beginning of their creation. This publicity determines that its audience is mostly ordinary people, and the most familiar and acceptable form for ordinary people is the round and embossed sculptures. Therefore, in the creation of contemporary public sculptures, the traditional techniques of round and embossed sculptures still dominate. Combined with the thematic and symbolic nature of the sculptures, ideas of creator are directly presented to the viewers with the cultural meaning of the works and the city's relationship.

\subsection{The application of traditional techniques in landscape and decorative sculptures}

The ornamental and decorative aspects of the landscape are, to some extent, to satisfy people's aesthetic needs. Landscape sculpture is a comprehensive public and environmental art. With the continuous development of people's humanity requirements for residential landscapes, it strives to bring viewers with beautiful feelings and confession, which is in line with the most essential spiritual needs of human beings. Decorative sculptures can use a variety of spatial styles to make them unique in sculptural art, such as the hollow technique of traditional sculptures. Hollow as one of the traditional techniques of sculpture expression, the greatest feature is that it can give the sculpture a visual sense of space and painting to make it not only emphasize the edge line features of the work, but also add a rich decorative effect to the work. In addition, more and more abstract sculptures appear in the construction of modern cities. These public sculptures do not have a very figurative form, giving people a special visual experience with a simple line or face or an overall abstract shape. The abstract sculpture is an element that extracts the "empty" element of the hollowing technique. It breaks through the established volume relations of the sculpture through hollow technique to make it transparent and extends the visual space to a great extent.

\subsection{The application of traditional techniques in architectural and stylistic sculptures}

With the development of science and technology and the diversification of sculpture language, all the styles appearing in the public sculpture field have all clearly reflected the diversity of public sculpture styles. Similar to architecture, sculptures appeal to the viewers in a direct way with specific visual feelings. Therefore, many sculptural techniques are borrowed from architecture. Architecture art uses a reasonable combination of styling, space, function and technology. The artistic values and cultural ideas that are expressed are relatively systematic and complete. As a kind of public space art modeling, public sculpture not only has a profound connection with style and aesthetic culture, but also learns from each other in the application of modeling language, public space relations, functional relations and technical materials.

In addition to architecture, similar to traditional sculptures, elements in painting are often applied to sculptures. In the creation process, a large number of drawing forms were introduced to organically combine two-dimensional vision with three-dimensional vision. With the emergence of various diversified forms of sculpture, contemporary public sculptures often do not follow the simple expression of traditional techniques in their creative techniques. For example, many urban public sculptures use the combination of various techniques such as round sculptures, relief sculptures and hollow sculptures in the same work to make the style of the work more prominent. 


\section{The Difference and Relation between Contemporary Public Sculpture and Traditional Sculpture}

There are both connections and differences between contemporary public sculpture and traditional sculpture. Due to the use of public space by contemporary public sculptures, it reflects to some extent its own publicity and its upholding relationship with the spirit of the times, and it also exhibits a cultural feature with significant regionality. The traditional sculpture has a very long history, even the primitive period and the feudal period. At that time, the city manifested a loose or dictatorial social form. There was little concept of citizens, and sculpture did not have to function as a public identity. This is one of the more significant differences between contemporary public sculpture and traditional sculpture. Second, public sculpture emphasizes the design to show the dialogue between works and space and the audience in creation. Its main purpose is to create a readability of urban space and sort out the spatial order of the city. In some cases, traditional sculptures can be used to transform into contemporary public sculptures, such as the Egyptian Sphinx and Michelangelo's David. These works originally used for political, religious or private collections have undergone changes in the times. They have gradually transitioned from the "private" nature to the cultural heritage of the nation along with the soundness of democratic systems. Under such conditions, traditional sculptures have been transformed into contemporary public sculptures, and the creative significance of their works has also undergone certain changes.

Due to regional differences, Chinese traditional sculptures also have different ways of creation. In the northern plains, hay and clay are used for drying and painting, such as Dunhuang grottoes, etc. In the south, wood carvings are used for the reasons of climate wetting. In some areas where technology is more advanced, cast copper is used. Traditional clay sculptures have very high requirements for techniques. It emphasizes that creators must have a high degree of intelligence in the implementation process, strictly follow the original ideas and plans and should not be arbitrarily changed and adjusted. In addition, traditional Chinese sculpture is very much about painting, and artists have superb ability to "carve good paintings". This kind of enrichment of the locality does not weaken the overall sense of shape. In fact, it has formed an echo to the whole. Traditional sculptures have a unique set of languages. There are also different ways to observe and express. Looking at the expression methods of contemporary public sculptures, it is influenced by the development of science and technology with rich and varied materials and flexible and changeable techniques. It is clear that technology is more conducive to the perennial preservation of sculpture than traditional sculpture techniques. And because of the public nature of space, contemporary public sculptures will be more sophisticated in this respect. Therefore, the technique of clay sculpture in traditional sculpture does not apply to public sculpture. However, some of the creative techniques are still followed in many works, such as the combination of sculpture and painting, but the material has been improved.

For contemporary public sculptures, looking for clues to creation in the past does not mean completely copying past techniques and forms. Instead, it is based on existing creative needs. On the basis of advancing with the times, the techniques applied to the past are applied to contemporary public sculptures to create more abundant and innovative public works for modern cities.

\section{The Application of Traditional Techniques of Contemporary Public Sculpture in Colleges and Universities}

With the diversified development of contemporary art, sculpture, as one of the important art forms of contemporary art, has long used more than just marble or bronze materials to reproduce a specific image in space. From the perspective of teaching content of the sculpture, the basic teaching of sculpture in the past mainly focused on the training of skills, including the shaping of body and the cultivation of realistic ability. However, after a long period of development, this training method seems to have become ineffective in the context of contemporary art development. 
The application of contemporary public sculpture in teaching has been more than just moderation and theorization. The emphasis on the traditional skills of contemporary public sculpture is the teaching concept that cannot be ignored in teaching.

\subsection{The topic of contemporary public sculpture in teaching}

The theme of contemporary public sculpture usually depends on many factors, such as the characteristics of public space, the historical and cultural traditions of the city, the crowds' characteristics and aesthetic habits of the city, etc. Therefore, the theme of any contemporary public sculpture is to some extent in conformity with the social space and historical culture of its environment. The design of contemporary public sculptures often takes into account both the artistry of his own form and the historical context of his city. In addition, the relationship with the surrounding environment, architecture or plants should also be well handled. Only in this way can we make better use of contemporary public sculpture in teaching and fully embody its artistic value. At present, some colleges and universities still use traditional landscape skits to achieve different expressions of contemporary public sculpture in social culture. Landscape sketches make it easy to create a rich artistic atmosphere and enable students to be inspired and inspired in the process of creation and viewing because of its controllability and convenience. However, when students implement the effect of landscape sketches in a wider public space, they will face many new problems. The creation process of the two has a very big difference. Therefore, in the teaching of contemporary public sculpture construction, it is also necessary to investigate and study according to actual conditions while adopting traditional techniques. The importance of modern sculpture in cultural construction has been highlighted from the manifestations of different fields, so that the traditional techniques of contemporary public sculpture can be deeply applied and embodied in teaching applications.

\subsection{Take its essence and abandon its dross from traditional techniques}

The traditional techniques of traditional Chinese sculpture have created many historically stunning works. However, its techniques must have its own dross due to the relatively long historical period. At present, colleges and universities should inherit the techniques applied to contemporary sculpture in traditional sculpture in the teaching of contemporary public sculpture. For example, the method of “stone styling” used in the stone carvings of Maoling Huo Qubing's tomb can be used under the current social ideology that calls for simplicity and respect for nature. The clay sculpture method adopted in traditional Buddhist grottoes is not conducive to long-term preservation due to the limitations of its materials. This should be understood by students but not recommended for continued use in teaching. In general, colleges and universities must not only have a full understanding of traditional techniques, but also learn to take its essence in the technical teaching of sculpture. Teaching should conform to the needs of the times under the traditional culture and achieve a richer, more historically connotative sculpture language for contemporary public sculpture.

\section{Conclusion}

The diversity and inclusivity of contemporary social culture determine that contemporary public sculpture inherits and innovates in traditional sculpture techniques. Colleges and universities should adhere to self-development and absorption of foreign ideas in the teaching of contemporary public sculpture. At the same time, colleges and universities must also learn to draw the essence from our country's traditions. In teaching, teachers must use the artistic concept of advancing with the times to make students feel the importance of public sculpture in the development of social civilization.

\section{References}

[1] Q. Z. Ma. Sculpture Space Public Art. Xuelin Press. 2004. 
[2] Y. Wen. Public Sculpture. Machinery Industry Press. 2006.

[3] F. Wang. Sculpture, Environment and Art. Southeast University Press. 2003.

[4] X. C. Feng. Iron Art Landscape. China Building Materials Industry Press. 2003.

[5] T. C. Wang and Y. T. Liu. Decorative Sculpture. China Textile Press. 2005.

[6] R. W. Lai. Ceramic Crafts Sculpture and Training. Liaoning Fine Arts Press. 2015.

[7] (Germany) Rolf Toman. Roman Style - Architecture, Sculpture and Paintings. China Railway Press. 2012.

[8] A. Q. Liu. Sculpture, Architecture and Environment. Tongji University Press. 2013.

[9] F. Xiao. The History of World Architecture and Sculpture. Liaohai Press. 2011.

[10] J. P. Yang. Chinese Sculpture. China Building Industry Press. 2010. 